\title{
EFFECTS OF TONSILLECTOMY ON VOICE ASSESSMENT
}

\author{
N. Devakanta ${ }^{1}$, T. Biram ${ }^{2}$, N. Lungleng ${ }^{3}$, N. Dhanachand Singh \\ ${ }^{1}$ Assistant Professor, Department of ENT, JNIMS, Porompat. \\ ${ }^{2}$ Senior Resident, Department of ENT, JNIMS, Porompat. \\ ${ }^{3}$ Assistant Professor, Department of ENT, JNIMS, Porompat. \\ ${ }^{4}$ Senior Resident, Department of Medicine, JNIMS, Porompat.
}

ABSTRACT

Removal of lymphoid tissue mass (Tonsils) from the vocal tracts between the vocal folds and lips may cause a change in voice quality postoperatively. This study was conducted to determine the effect of tonsillectomy on voice in terms of its quality under the Category: Hoarse, Harsh and Breathy. This study was done on 50 patients ( 32 females and I8 males) who underwent tonsillectomy for chronic tonsillitis during a period from January 2004 to February 2005 in a Tertiary Care Centre. The preoperative and postoperative voice samples of vowels /a/, /i/ and /u/ were recorded in a computer. The recordings were analyzed using a computerised programme, Dr Speech Software Version 4 (Tiger DRS, Inc. Seattle, USA). The patients reported that they did not perceive any change in his/her voice after surgery. The vocal assessment between the preoperative, first postoperative followup and second postoperative follow-up for all the three vowels /a/,/i/ and /u/ were not statistically significant. As a conclusion, tonsillectomy do not appear to change the acoustic features of vowels remarkably, but in professional voice users they should be warned for any possible changes in voice after surgery.

\section{KEYWORDS}

Tonsillectomy, Hoarse, Harsh, Breathy, Acoustic Analysis.

HOW TO CITE THIS ARTICLE: N. Devakanta, T. Biram, N. Lungleng, N. Dhanachand Singh . "Effects of Tonsillectomy on Voice Assessment." Journal of Evolution of Medical and Dental Sciences 2015; Vol. 4, Issue 102, December 21; Page: 16769-16770,

DOI: $10.14260 /$ jemds/2015/2513

\section{INTRODUCTION}

Tonsillectomy is one of the most performed surgeries worldwide to treat upper respiratory tract infections and/or obstructive diseases. Surgeons performing an appreciable number of tonsillectomy commonly observed and alteration in the voice at a week's postoperative visit.

The removal of tonsils can modify the shape of vocal tract and it is assumed that the acoustic features of voice may change after tonsillectomy. But the question is whether these changes in the acoustic features of vowels are minimal or do they have effects on professional speakers and singers, since any change in voice may interfere with their professional jobs.

Presently acoustic analysis of voice is one of the most attractive methods of assessing the phonatory functions providing the quantitative and qualitative data. In this study, the effects of tonsillectomy on the voice assessment is analyzed.

\section{MATERIAL AND METHODS}

This prospective study was carried out on 50 patients (32 females and 18 males), above 5 years of age. All of them underwent tonsillectomy for having recurrent episodes of tonsillitis. All children below 5 years, patients with congenital anatomical defects of nose and palate and change of voice during puberty were excluded from the study. The patients were required to sustain the vowels $/ \mathrm{a} /, / \mathrm{i} /$ and $/ \mathrm{u} /$ and their voices were recorded preoperatively one day before the surgery and postoperatively one week after the surgery and

Financial or Other, Competing Interest: None.

Submission 11-12-2015, Peer Review 12-12-2015,

Acceptance 17-12-2015, Published 21-12-2015.

Corresponding Author:

Dr. N. Devakanta Singh,

Assistant Professor

Department of ENT,

JNIMS, Porompat, Imphal-795004.

E-mail: devakanta@gmail.com

DOI:10.14260/jemds/2015/2513 one month after the surgery.

These recordings were made in a computer and analyzed by computerized Dr Speech Software Version 4 (Tiger DRS, Inc. Seattle, USA).

The difference between the mean scores of preoperative, postoperative stage I and postoperative stage II for all the three vowels /a/, /i/ and / $\mathrm{u} /$ under the category: Hoarse, Harsh and Breathy were studied and statistically analyzed.

\section{RESULTS}

In the present study, maximum cases of tonsillectomy were seen in the age group of 5-11 years accounting for 32 percent of the total cases. The minimum cases of tonsillectomy were seen in the age groups of 19-25 years accounting for 18 percent only.

Results for the vocal assessment between the preoperative and postoperative stage I and postoperative stage II for the three vowels /a/, /i/ and /u/ are shown in the tables mentioned below.

\begin{tabular}{|c|c|c|c|}
\hline \multirow{2}{*}{$\begin{array}{c}\text { Voice } \\
\text { Quality }\end{array}$} & Mean Scores for Vowel /a/ & \\
\cline { 2 - 4 } & Preoperative & Postoperative I & $\begin{array}{c}\text { Post } \\
\text { operative II }\end{array}$ \\
\hline Hoarse & 1.2 & 1.7 & 0.9 \\
\hline Harsh & 0.8 & 1.3 & 0.8 \\
\hline Breathy & 1.7 & 1.6 & 1.3 \\
\hline \multicolumn{2}{|c|}{ Table 1: Showing the vocal assessment between } \\
preoperative, postoperative stage I and postoperative \\
stage II (for vowel/a/) \\
\hline
\end{tabular}

\section{Hoarse}

The difference in the mean values between one stage to another stage was not statistically significant ( $p>0.05)$.

\section{Harsh}

The difference in the mean values between one stage to another stage was not statistically significant ( $p>0.05)$. 


\section{Breathy}

The difference in the mean values between one stage to another stage was not statistically significant $(\mathrm{p}>0.05)$.

\begin{tabular}{|c|c|c|c|}
\hline \multirow{2}{*}{$\begin{array}{c}\text { Voice } \\
\text { Quality }\end{array}$} & Preoperative & Postoperative I & $\begin{array}{c}\text { Postoperative } \\
\text { II }\end{array}$ \\
\cline { 2 - 4 } & 2 & 1.7 & 1.6 \\
\hline Hoarse & 1.4 & 1.5 & 1.5 \\
\hline Harsh & 2.4 & 2.3 & 2.0 \\
\hline Breathy & \multicolumn{3}{|c|}{ Mean Scores for Vowel /i/ } \\
\hline \multicolumn{2}{|c|}{ Table 2: Showing the vocal assessment between the } \\
preoperative, postoperative stage I and postoperative stage II \\
(for vowel/i/)
\end{tabular}

\section{Hoarse}

The difference in the mean values between one stage to other stage was not statistically significant $(p>0.05)$.

\section{Harsh}

The difference in the mean values between one stage to other stage was not statistically significant $(p>0.05)$.

\section{Breathy}

The difference in the mean values between one stage to other stage was not statistically significant $(\mathrm{p}>0.05)$.

\begin{tabular}{|c|c|c|c|}
\hline \multirow{2}{*}{$\begin{array}{c}\text { Voice } \\
\text { Quality }\end{array}$} & Preoperative & $\begin{array}{c}\text { Postoperative } \\
\text { I }\end{array}$ & $\begin{array}{c}\text { Postoperative } \\
\text { II }\end{array}$ \\
\cline { 2 - 4 } & 2.2 & 2.4 & 2.0 \\
\hline Hoarse & 2.0 & 2.2 & 1.8 \\
\hline Harsh & 2.9 & 2.6 & 2.4 \\
\hline Breathy & \multicolumn{3}{|c|}{$\begin{array}{c}\text { Table 3: Showing the vocal assessment between the } \\
\text { preoperative, postoperative stage I and postoperative stage II } \\
\text { (for vowel /u//) }\end{array}$} \\
\hline \multicolumn{3}{|c}{}
\end{tabular}

\section{Hoarse}

The difference in the mean values between one stage to other stage was not statistically significant $(p>0.05)$.

\section{Harsh}

The difference in the mean values between one stage to other stage was not statistically significant $(p>0.05)$.

\section{Breathy}

The difference in the mean values between one stage to other stage was not statistically significant $(p>0.05)$

\section{DISCUSSION}

The effects of tonsillectomy on voice have not been studied extensively in terms of voice quality, other than its effect on nasalance. $(1,2)$ Few studies have examined voice changes in post tonsillectomy patients. In general minimal changes were found. $(3,4,5,6)$

Tonsillectomy can modify the shape of the vocal tract by enlarging the resonating chamber and by altering the formant frequencies or by altering conformation of tonsillar fossa. $(1,4)$ With respect to the supralaryngeal factors if extirpation of soft tissue from the oropharynx altered the anatomy of the supralaryngeal acoustic transmission pathway and possibly the dynamics of physiologic function, the acoustic measures related to vocal tract resonance could be changed.(1)

With regard to vocal assessment in our study of vowels /a/, /i/ and / $\mathrm{u} /$ under the category: Hoarse, Harsh and Breathy; the results were found to be not statistically significant. Saida et al.(3) reported that tonsillectomy did not appear to change the acoustic features of vowels remarkably.

Hori et al.(4) noted that the changes in articulation were considered to be negligible in clinical practice. Chuma et al.(1) reported that it had only minimal impact on quantitative and qualitative aspect of vocal function.
Antonio et al.(7) reported that the perceptual speech characteristics improved or remain the same for most variables. However, rating of voice quality (Pitch and breathiness) were significantly improved after surgery.

Patients may be advised the possibility of voice change after surgery, especially if they are professional voice users. According to Behrman et al.(8) one-fifth of patient's voice have improved after surgery and none thought the voice to be worse.

A retrospective study done by Jarboe et al.(9) stated that the patients voices were not impaired after tonsillectomy. The gathered information in his study also suggests that tonsillectomy can be performed safely in vocal performing artists despite their specialized requirements for pharyngeal function. Ilk, Erogul.(10) and his colleagues reported the changes were minimal and have little effects on acoustic parameters except for the professional speakers and singers. Therefore, the changes in voice quality were considered to be negligible, although it seemed to be a problem that cannot be disregarded.

\section{CONCLUSION}

From the present study it can be inferred that the situation of vocal analysis and assessment for the vowels /a/, /i/ and /u/ under the categories Hoarse, Harsh and Breathy remain more or less the same during the preoperative stage, first postoperative follow-up and the second post-operative followup.

These results demonstrate that tonsillectomy did not appear to change the acoustic features of vowels remarkably; however, it is advisable to warn the professional voice users for possible subtle changes in voice parameters after surgery.

\section{REFERENCES}

1. Chuma AV, Cacace AT, Rosen R, et al. Effects of tonsillectomy and/or adenoidectomy on vocal function: laryngeal, supralaryngeal and perceptual characteristics. Int J Pediatric Otolaryngol 1999;(47):1-9.

2. William RG, Preece M, Rhys R, et al. The effect of tonsil surgery and adenoid surgery on nasalance. Clin Otolaryngol 1992 Apr;17(2):136-40.

3. Saida H, Hirose H. Acoustic changes in voice after tonsillectomy Acta Otolaryngol. Suppl 523, 1996;239-41.

4. Hori Y, Koike Y, Ohyama G, et al. Effects of tonsillectomy on articulation. Acta Otolaryngol Suppl 523, 1996;248-51.

5. Tang P, Wilbur LJG, Fukazawa T. Acoustic analysis of voice in tonsillectomy. J Voice 1989;(3):81-86.

6. Brosch S, Mathes C, Pirsig W, et al. Uvulopalatopharyngoplasty with tonsillectomy changes the fundamental frequency of voice: a prospective study. J Laryngol Otol 2000;(114):113-18.

7. Antonnio LL, Snyder LS, Samadani S. Tonsillectomy in children with or at risk for velopharyngeal insufficiency: effect on speech. Oto Laryngology HNS, 1996 Oct; 115(4):319-23.

8. Behrman A, Shikowitz MJ, Dailey S. The effect of upper airway surgery on voice. Otolaryngol Head Neck Surg 2002;(127):36-42.

9. Jarboe JK, Zeitels SM, Elias B. Tonsillectomy and adenoidectomy in singers J Voice 2001;(15):561-4.

10. Ilk HG, Erogul O, Satar B, et al. Effects of tonsillectomy on speech spectrum. J Voice 2002 Dec;16(4):580-6. 